\title{
Can We Hedge an Investment Against A Potential Unexpected Environmental Disaster?
}

\author{
George Halkos ${ }^{1} \cdot$ Argyro Zisiadou $^{1}$ (D)
}

Received: 5 June 2020 / Accepted: 23 February 2021 / Published online: 2 August 2021

(c) The Author(s), under exclusive licence to Springer Nature Switzerland AG 2021

\begin{abstract}
The purpose of this paper is to examine whether there is a possible hedging technique against a potential unexpected hazard, that can secure the capital invested by individuals or corporations. More specifically, the traditional hedging techniques are presented and illustrating whether they can be applicable against unexpected environmental disasters. Moreover, the evolution of hedging techniques regarding the catastrophe disasters are presented in the papers. After illustrating hazard-prone areas with the use of mapping visualization, techniques or catastrophe risk management and risk minimizations are proposed in an attempt to reduce the direct and indirect losses after a disastrous events while at the same time increase the trustworthiness of corporations and governments.
\end{abstract}

Keywords Hedging · Catastrophe risk management · Insurance industry · Hazard-prone areas

\section{Introduction}

On the circles of the financial sector there is a well-spread knowledge regarding the rational investors' preferences. Investors are usually assumed to be rational, so if we ignore the arbitrage case, they tend to choose more "safe" investments which will allow them to maximize their profits, or in other words minimize potential risk they receive by investing (Merton 1969; Cohn et al. 1975; Benartzi and Thaler 1995, 1999; Campbell and Cochrane 1999; Ait-Sahalia and Lo 2000; Jackwerth 2000; Rosenberg and Engle 2002; Brandt and Wang 2003; Gordon and St-Amour 2004; Bliss and Panigirtzoglou 2004; Haigh and List 2005; Bollerslev et al. 2011; Halkos et al. 2017).

Hedging and portfolio diversification may appear to be efficient in reducing the potential loss of an investment. Great attention has been drawn about the advantages of portfolio diversification (Búgar and Maurer 2002). Jennings and Graham (1987) have mentioned the

George Halkos

halkos@uth.gr

Argyro Zisiadou

zisiadou@uth.gr

1 Laboratory of Operations Research, Department of Economics, University of Thessaly, Volos, Greece 
ability of transferring the risk of investment through hedging, while Bond and Thompson (1985) underlying that the size of the optimal hedging ratio is one of the main determinants used by the decision makers apart from cash position of the corporation. Although the potential loss of capital can be reduced using techniques such as hedging and portfolio diversification, there are some cases in which the potential loss cannot be predicted. The act of nature is such a case (Halkos and Zisiadou 2018a). Nature acts independently, and a common example of that independence is the tectonic plate movement (Halkos and Zisiadou 2018a). Distinguished sciences such as geology and seismology, do have the techniques to monitor, observe and examine the geophysical events caused by those tectonic plate movements.

The purpose of this paper is to examine whether there is a possible hedging technique against a potential unexpected hazard, that can secure the capital invested by individuals or corporations. The structure of the paper is as follows. Section 2 reviews the existing relevant literature regarding the catastrophes and available hedging techniques while Section 3 provides information regarding the catastrophe risk management and preparedness. Finally, Section 4 concludes the study providing important statements and fundamentals for further research.

\section{Catastrophes and Hedging Techniques}

The first question that needs to be answered regarding the hedging techniques is "Who is responsible for which hedging strategy should be followed?" The answer to this question differs to the type of the investment we are handling. If this question is raised by individual investors who are placing their money to corporations' stocks or governments' bonds, then the answer is quite simple. The investment advisor will consider the risk level the investor is willing to accept and then he/she will propose possible hedging techniques to minimize the potential loss of capital. In such cases, one of the most common techniques, if not the most popular, is the portfolio diversification.

On the other hand, when this question is raised into a corporation and among the board of directors, the answer is not so plain. As mentions by Stulz (1984), shareholders do not have the ability to decide which hedging policy the corporation will follow. Responsible for such decision are the managers of the firm. In other words, the manager of a firm should be able to protect the capital of the corporation as well as the current liquidity status and the firm's reputation. For that reason, a capable manager is the one that will be well-informed and well-educated in order to know the possible threats the corporation may face as well as predict them. This knowledge will allow them to create the optimal hedging policy.

The same paper (Stulz 1984) raised the impact of hedging cost to the managers' decision. One of the main assumptions is that the manager can implement a hedging strategy costlessly. Under that assumption, shareholders do not interfere to the managers' decisions regarding the hedging strategy. What is important to mention though, is the fact that sometimes a hedging strategy may have a remarkable cost. Although the shareholders are not those who will decide the hedging policy of the corporation, they have the right to forbid and cancel the managers' decision for a costly policy. Such an action, though, it may not have desirable results. Stulz (1984) underlined the fact that the managers may use techniques that will probably be undetectable by the shareholders. If the managers are not allowed to hedge using a straightforward hedging strategy due to the cost and the barriers set by the shareholders, then the most common technique is to reject projects with a 
positive net present value. Having that said, hedging policies for unexpected phenomena have discouraging costs and may raise great conflict between managers and shareholders.

Another great question raised regarding hedging policies is in what way an optimal hedging technique will benefit a corporation. In order to be able to answer that question we need to take into consideration the statement Mello et al. (1996) and Mello and Parsons (2000) underlined regarding the Futures. Among all hedging choices, Futures often provide the most liquid and convenient instruments for managing risk. A disadvantage though is the fact that we cannot simultaneously hedge cash flows since future contracts are marked to market. The liquidity aspect of the futures is what makes them more desirable. The reason to that is the fact that the optimal hedging policy of a corporation is the one that maximizes the firm's liquidity in the form of excess cash and/or unused debt capacity. The benefit of such situation is that it minimizes the potential risk of financial distress.

The importance of liquidity is not so superficial. A corporation that can ensure its liquidity status can certify its credibility. More specifically, one of the main factors taken into consideration by credit rating agencies is the liquidity of a corporation, or government if a country is examined. In other words, liquidity may affect the credit rating of a corporation and/or government, a criterion commonly used by analysts when examining the trustworthiness and reputations or firms and nations. A speculative credit rating is discouraging for investors as well as for lenders. In other words, the credit rating of a country or corporation is one of the most common rates that mirror potential risk the investor is about to perceive by investing on this specific bond or stock.

Another aspect that may influence investors' decisions is a recorder reduction of production. Reduced productivity may affect investors' perceptions causing fluctuations in the share price or even volatility in its broad of directors. If we consider in our analysis the case of unexpected disasters, both natural and technological, then we must underline the aftermath of such events. During such an occurrence, we encounter both direct and indirect impacts. Smith (1996) recorded as direct impacts the fatalities caused by the disaster, the injured citizens and as well as the loss of properties. However, those direct impact tend to cause indirect ones. The increased number of injured citizens lead to an increase of excess need of paramedic sources, leading to an increase of the governments' health expenditures. The most recent case of unexpected natural environmental hazard that underlines all the negative impacts is the COVID-19 pandemic. What is important to mention is that all the pandemic are included on the natural biological environmental hazards under the category of epidemics. A great number of researchers have investigated and discussed the consequences of that unexpected phenomenon both to the individuals and the economy in general over the last year (Gharehgozli et al. 2020; Martin et al. 2020; Mandel and Veetil 2020; Katafuchi et al. 2020; Kurita and Managi 2020). Property losses, on the other hand can affect both the individuals who eventually become homeless, and the corporations/governments which lose their facilities. Demolished building lead to loss of fixed assets which immediately decreases the productivity and increases the cost of replacement. Although disasters are associated with risk, investors tend to have a different perspective regarding the source of the disaster. ${ }^{1}$

More specifically, if a country is facing a natural disaster, where no one can be blamed for, foreign investors who may hold this country's bonds will continue to trust the country due to the "innocence" of the country. On the other hand, when a firm causes a

\footnotetext{
1 A detailed review of terminology regarding disasters and all criteria taking into consideration when characterizing an event as disaster is given in Halkos and Zisiadou (2018a).
} 
technological disaster, such as a nuclear power plant explosion, will probably have to face adverse effects such as defamation and its consequences. More specifically, a corporation causing an environmental accident may record client losses which will eventually lead to a decrease of liquidity with all the side effects that this may have. At the same time, investors will "punish" the firm by selling its shares at any price to avoid a bigger loss, if this corporation is publicly traded. In such cases, corporations may lose trustworthiness. However, this is not always the case. As it is mentioned by Halkos and Zisiadou (2020), specific corporations which can guarantee their high profitability such as corporations of the oil industry, do not face a negative impact of their share prices, indicating that investors may ignore the environmental disaster due to the fact of the high earnings through dividends.

Regarding the unexpected environmental disasters, another common tool corporation use in order to transfer and reduce risk is the insurance technique. By insuring their assets, the firms transfer to risk of loss to the insurance agency. This policy, however, caused a great concern to the insurance industry. O'Brien (1997) mentioned the disquiet influencing the insurance industry regarding the need of additional capital sources in order to be able to cover the financial risk posed by natural catastrophes. This disquiet meant to be the forerunner of the catastrophe insurance options. The Florida Residential Property and Casualty Joint Underwriting Association in 1995 was negotiating a 1.5-billion-dollar line of credit. A similar alternative was proposed by Samuel Fortunato, a former New Jersey Insurance Commissioner, who offered the approach of Catastrophe Risk Exchange (Catex). Those transactions were characterized by the transfer or exchange of risk among insurers or reinsurers.

Based on the common hedging policies, Chicago Board of Trade in 1992 proposed the Insurance Derivatives which were basically, catastrophe insurance futures and options. However, catastrophe insurance futures did not appear to gain interest among insurers and their trading stopped in 1995. Catastrophe insurance options, on the other hand, appeared to be more successful due to their similarity with the protection afforded by reinsurance layers. The fact that the premium estimated was based on the most recent statutory annual statement filed by the reporting companies led the insurance industry to not fully accept those options as a hedging tool. For hat reason, in 1995 the Chicago Board of Trade introduced the PCS Options, which are index options having as a measuring the amount of catastrophe claims in the region and the period of the contract.

The PCS Options have 3 main advantages over the reinsurance policy. Firstly, the options provide a standardize contract that has no negotiation with a reinsurer. Secondly, they have a rapid execution. Last but not least, the insurer has the ability to adjust the hedge throughout the contract period in response to claims experience. On the other hand, their biggest disadvantage is their effectiveness compared to the reinsurance. If the estimate of the relative claims ratio is far from the actual outcome, the pcs could be either quite pleasant or unpleasant based on the direction of the discrepancy. Another drawback is the fact that there is no generally accepted approach for the options price determination.

Although a great discussion is taking place throughout the years regarding corporations and insurance industries against the catastrophes, it is important to mention that catastrophes, both natural and technological, heavily affect the countries either on regional or national level. An interesting difference is lying between the developed and developing countries. By using a line from Smith's (1996) book, we can emphasize that difference. As Smith (1996) mentioned “...poor lose their lives and rich lose their money". And that difference, between developed and developing countries is also underlined by Freeman (2001), who made a distinction on the way those groups of countries cope with the catastrophes. 
More specifically, based on Freeman (2001), World Bank as well as other International Financial Institutions encountered two financial issues occurred by natural catastrophes. On the one hand, there is the increasing demand from developing countries for financial support after a natural hazard occurrence and on the other hand, there are the non-increasing limited budgets against the demanding financial support. In an attempt to cope with that financial issue, the institution have considered the catastrophe hedges as a possible tool to provide post-disaster reconstruction financial relief to the developing countries. Additionally, as Pollner (2001) mentioned through the years World Bank and other financial institution have sponsored research attempts which investigated the role of private market to the post-disaster financing.

The option o hedging may have been proposed as a possible tool to the developing countries but as Freeman (2001) emphasized, it is important to understand if there is any benefit for a developing, or poor as it is mention, country to place its limited economic resourced to hedge against a catastrophe. The answer to that dilemma is based on a cost benefit analysis. In other words, if the cost of hedging is greater that the cost of the potential disaster, the hedging policy is rejected, and the country will bear the economic negative impact that the catastrophe will bring. Similarly, if the cost of the catastrophe is greater compared to the hedging strategy, then the hedging strategy is preferable. As it is also mentioned, if the government fails to provide risk shifting opportunities, all the disaster-related cost is bared to the victims.

Regarding the developed countries, as Freeman (2001) mentioned, natural catastrophe derivates appeared to be one of the most important innovations in the field of catastrophe risk management. Risk shifting for catastrophe losses was occurred through insurance and as it is widely proved that technique appears to be efficient when a large number of independent risks is combined. As Hodgson (1997) mentioned, under the law of large numbers, the probability of each measured event of a given type tends to approach the mean probability of all aggregated events. However, is it crucial to mention that natural catastrophes, or at least events, are not independent. There is proven to be a connection between two or more, either natural or technological, disasters. A well-known example of such a combined disaster is the Fukushima Daiichi Nuclear Power Plant disaster occurred in 2011 as described by Halkos and Zisiadou (2020). An earthquake occurred in the ocean, created a tsunami that caused a flood which eventually led to the shutdown of the reactor of the power plant. This is a strong example establishing the correlation between the catastrophes, which is against the law of the large numbers.

The catastrophe-linked derivates were also discussed by Freeman (2001) emphasizing the benefit of unlimited capacity that the capital market provides to those tools, compared to the limited capacity the path of insurance. Doherty (1997) underlined the advantage of the catastrophe-derivatives having a competitive price in the long term compared to the traditional methods, however, history proved that these derivatives were not preferable.

\section{Catastrophe Risk Management and Preparedness}

The insurance industry was globally challenged by the catastrophe risk. Insurers were evaluating the financial coverage of losses based on the statistically measurable and predictable distribution of events (Pollner 2001). Moreover, as Pollner (2001) mentioned, catastrophic events are less frequent while causing a large number of potential losses. Catastrophe events, both natural and technological hazards, are characterized as unexpected processes 
Fig. 1 Map of OccurrenceGeophysical Hazards

\section{Geophysical Occurrence}
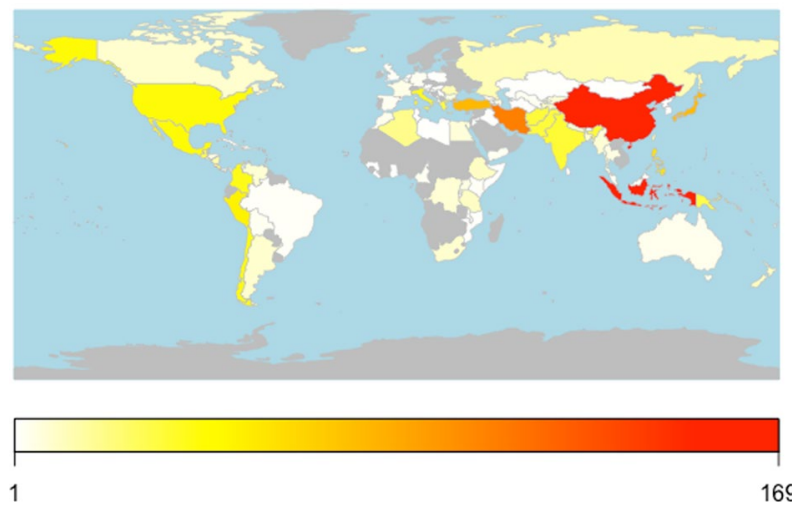

in terms of occurrence. And this statement is actual up to a point. The scientists may not be able to predict with a high level of accuracy the place where the next unexpected event will occur or the exact magnitude this event will have, however, specific techniques which can illustrate the high-risk areas of each random event do exist. Using techniques which are based on frequencies may let us conclude to assumptions that can be used as a priori information. The first requirement, based on Pollner (2001) is to set meaningful and workable risk criteria.

Although there is a perception that natural phenomena are unexpected and occur randomly, there is evidence to suggest that, partially, the assertion of randomness is not valid. More specifically, there is a proven regional distribution regarding the geophysical events, initially mentioned by Bolt (1988) as the "Ring of Fire". Based on CRED database (EMDAT 2017) and with the use of R-studio packages and routines, maps of occurrence have been created for different types of disasters over the last 197 years (Halkos and Zisiadou 2018a, b, c, 2019, 2020). The technique of hazard mapped locations was also discussed by Pollner (2001) proposing it as a tool to illustrated high-risk and low-risk areas in an attempt to help the insurers establish the risk-based premium pricing. In this section, we are providing evidence for some of the most common catastrophes over the last 117 years as reported by the EM-DAT (2017).

Beginning with one of the most disastrous cases, Fig. 1 illustrates the occurrence of the Geophysical Hazards (Halkos and Zisiadou 2018a, 2020). What it can be seen, is the approval of the Ring of Fire region. In other words, although we do not know exactly when the next geophysical hazard (ground movement, tsunami, volcanic activity) may occur, we do know the prone areas.

Moreover, there as specific characteristics of each event that may give further information. An example may be the tsunami case which will only affect the coastal regions. This a priori information gives the insurers as well as the policy makers the knowledge that coastal regions that belong to the Ring of Fire have higher possibilities of facing an upcoming tsunami.

Moving forwards to another category of natural disasters, Fig. 2 illustrated the overall climatological events occurrent since 1900 (Halkos and Zisiadou 2018a). As it can be seen, once again there is a space concentration of underlying events. More specifically, Eastern Asia, Oceania, and Americas (North, Central and South) together with Russia are the most 
Fig. 2 Map of Occurrence-Climatological Hazards
Climatological Occurrence
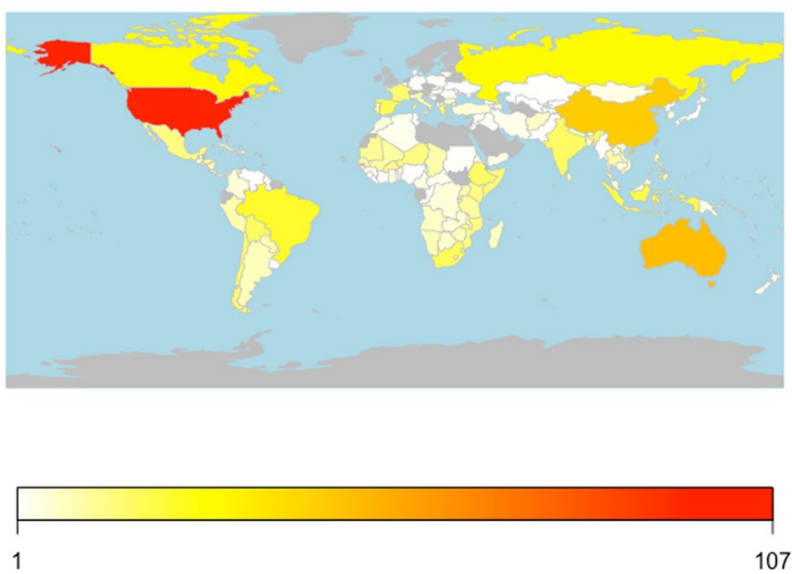

Fig. 3 Map of OccurrenceMeteorological Hazards

\section{Meteorological Occurrence}

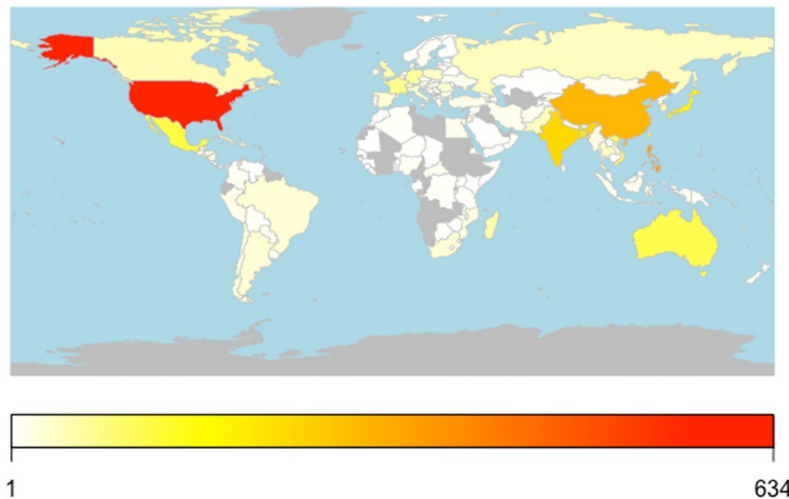

affected regions. However, U.S.A appear to be the region which suffered the most leading us to the conclusion this high-risk area is more prone to face a new catastrophe that is related to the climatological hazards. The governments and policy makers of those regions should probably take into consideration those evidence and create preparedness plans in advance.

Another known category of natural hazards is the Meteorological. As it has been illustrated by Halkos and Zisiadou (2018a), Fig. 3 summarizes the meteorological events by country since 1900. This case differs from the two previous categories. In the previous categories analyzed, an overall spread of events is illustrated, with some highly risky areas pointed out. In contrast, the meteorological hazards appeared to be concentrated to specific countries around the globe. Once again, the country that faces the most disastrous events is the U.S.A followed by the Eastern part of Asia as well as Australia.

Last but not last, a technological type of hazard is presented in an attempt to prove that not only the natural catastrophes are space concentrated but also the technological ones. More specifically, Fig. 4 (Halkos and Zisiadou 2019, 2020) pictures the industrial accidents occurred over the last 117 years as reported by EM-DAT (2017). Similarly, to the 
Fig. 4 Map of OccurrenceIndustrial Hazards

\section{Industrial Occurrence}
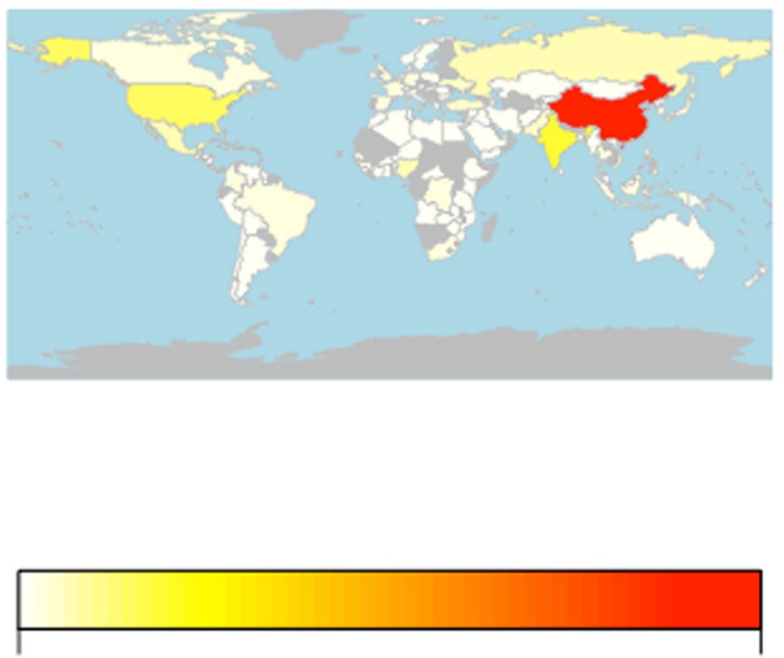

meteorological case, there is a high-risk area indicated in the map, underlining that most industrial accidents occur to the Eastern region of Asia. Knowing that evidence in advance, we have enough information to create an investment policy. Individual investors who prefer to invest on countries or corporations of this regions have the a priori information that a potential industrial disaster may occur. At the same time, corporations that bestir themselves on that region may probably need to take extra protection measures and create preparedness plans in order to avoid an upcoming industrial disaster, or at least minimize the possibility of occurrence. Alongside to the corporations, governments should run more security tests to the corporations that are prone to cause similar accidents. These are some basic activities that can be done beforehand when knowing the potential risk that we are facing.

In other words, although the exact place and time of an upcoming catastrophe cannot be predicted, based on evidence, we know a priori, which regions are more prone to face another disaster. This information may influence the manageable part of the risk. Based on Pollner (2001), there is a great potential for structural risk reduction based on the knowledge of the hazard prone areas. The term of structural indicated the use of building codes as well as appropriate construction materials as established by scientists. Another proposal for such cases is the extended use of protective devices when this is applicable. Apart from the structural category, there is also the non-structural category that includes features that can not be changes such as hazard-prone areas, which however if they are identified correctly can be least used, if not avoided at all.

Due to the possibility of a new catastrophe, governments and corporations should pay more attention to those high-risk areas as an attempt to reduce possible losses (Viscusi 2006). Taking into consideration all the a priori information, and the What is interesting though is that, although we were expecting a space concentration regarding natural events, the assertion of regional distribution is also observed in the case of industrial hazards. As 
it has already been mentioned, one of the most important advantages a priori information can give is the ability to create better and well-structured preparedness plans. Both corporations and governments should be able to minimize the potential risk they are facing. For the risk that cannot be reduced, they should be able to handle of the direct and indirect losses that will eventually occur.

Countries which are located to specific hazard-prone areas should evaluate their building codes while at the same time examine the existing building, both private and public, in an attempt to repair any construction failure in advance. Alongside with the technical measures, the governments should inform and educate their citizens on how to react when a hazard occurs and what they should do after the occurrence. In that way, the citizens will know what they will face, and this condition will help them reduce the uncertainty and any poor risk management as individuals. This will not only increase the safety of the public during a disaster but also the trustworthiness the citizens will have for the government.

\section{Conclusions}

Risk aversion is the main determinant that influences investors' choice. Thus, when investment advisors diversify a portfolio they should always take into consideration first of all investors' preferences and their tolerance to risk as well as any aspect that may lead to money loss. Uncertainty, on the other hand, is the main characteristic of capital markets, with the idea "the more you risk, the more you gain". Although analysis techniques for stock performances exist, these models cannot capture potential risk of "unexpected". Environmental hazards, which are assumed to be random, have a significant impact to the society and influence everyone's life.

Initially, we have presented that although the traditional hedging techniques are not applicable to the catastrophe events, corporations have transferred the potential risk to the insurance industry. After the financial pressure the insurance industry faced, it was decided to create similar hedging tools that can be traded in order to reduce their financial distress. World Bank and other international financial institutions decided to participate on that attempt by sponsoring researches after the financial pressure the faced by lending financial resources to the developing countries as post-disaster relief.

Moreover, we have proven that neither natural, and more specifically geophysical, nor technological, and more specifically industrial hazards are random. Based on our previous research (Halkos and Zisiadou 2018a, b, c, 2019, 2020) both cases have high- and low-risk areas, so probability of occurrence may be predicted up to a certain point. If investment advisors know a priori the possibility of an environmental hazard, natural or technological, they may be able to diversify portfolios of high-risk areas by including assets from low-risk areas as well. Moving forward, it has been shown, based on events list used and dataset we worked on, investors are not significantly reacting to major na-tech hazards. In other words, their investment strategic plan does not change when an unexpected environmental disaster occurs.

Having all this information beforehand, we believe that governments may have the opportunity to create better security and rescuing plans, as well as preparedness systems, while at the same time be able to cover possible damages with emergency payments from their annual budgets. Investment advisors, as we have already mentioned, may help their clients to diversify or hedge in a way that will minimize potential risk, without avoiding investment on specific corporations or countries. Furthermore, our paper provides evidence 
that some macroeconomic factors may have an effect on investors' psychology regarding their investment decision after occurrence of an unexpected environmental disaster. We can infer that reputation of a country or corporation may be a decisive factor.

Supplementary research could be done by including events from other categories of unexpected events such as transport accidents, meteorological hazards etc., or by expanding the time span of the event analysis. Although we would like to include cases such as Chernobyl Nuclear accident or Three Mile Island, the lack of available information reduced our sample. Moreover, further research could be carried out with inclusion of more macroeconomic factors or with use of other advanced econometric methods on modelling such issues. Inclusion of other explanatory variables like governmental announcements, such as bankruptcy, or the rinse of an extremist political party may be also useful. Likewise, announcements of downgrade/upgrade of countries or corporations from Credit Rating Agencies may lead to useful knowledge on how investors may weight their risk based on available information.

Supplementary Information The online version contains supplementary material available at https://doi. org/10.1007/s41885-021-00085-4.

Acknowledgements This work has been supported by the General Secretariat for Research and Technology and the Hellenic Foundation for Research and Innovation (HFRI).

\section{References}

Ait-Sahalia Y, Lo AW (2000) Nonparametric risk management and implied risk aversion. J Econ 94(1-2):951. https://doi.org/10.1016/S0304-4076(99)00016-0

Benartzi S, Thaler RH (1995) Myopic loss aversion and the equity premium puzzle. Q J Econ 110(1):73-92. https://doi.org/10.2307/2118511

Benartzi S, Thaler RH (1999) Risk aversion or myopia? Choices in repeated gambles and retirement investments. Manage Sci 45(3):364-381. https://doi.org/10.1287/mnsc.45.3.364

Brandt MW, Wang KQ (2003) Time-varying risk aversion and unexpected inflation. J Monet Econ 50(7):1457-1498. https://doi.org/10.1016/j.jmoneco.2003.08.001

Bliss RR, Panigirtzoglou N (2004) Option-implied risk aversion estimates. J Financ 59(1):407-446. https:// doi.org/10.1111/j.1540-6261.2004.00637.x

Bollerslev T, Gibson M, Zhou H (2011) Dynamic estimation of volatility risk premia and investor risk aversion from option-implied and realized volatilities. J Econ 160(1):235-245. https://doi.org/10.1016/j. jeconom.2010.03.033

Bolt BA (1988) Earthquakes. W.H Freeman and Company, New York

Bond GE, Thompson SR (1985) Risk aversion and the recommended hedging ratio. Am J Agric Econ 67(4):870-872

Bugár G, Maurer R (2002) International equity portfolios and currency hedging: the viewpoint of German and Hungarian investors. ASTIN Bulletin: The Journal of the IAA 32(1):171-197

Campbell JY, Cochrane JH (1999) By force of habit: A consumption-based explanation of aggregate stock market behavior. J Polit Econ 107(2):205-251

Cohn RA, Lewellen WG, Lease RC, Schlarbaum GG (1975) Individual investor risk aversion and investment portfolio composition. J Financ 30(2):605-620. https://doi.org/10.1111/j.1540-6261.1975.tb018 34.x

Doherty NA (1997) Financial innovation in the management of catastrophe risk. J Appl Corp Finance 10(3):84-95

EM-DAT (2017) The International Disaster Database, Centre for Research on the Epidemiology of Disaster - CRED, http://www.emdat.be, Accessed: 5 May 2017

Freeman PK (2001) Hedging natural catastrophe risk in developing countries. The Geneva Papers on Risk and Insurance. Issues Pract 26(3):373-385

Gharehgozli O, Nayebvali P, Gharehgozli A, Zamanian Z (2020) Impact of COVID-19 on the Economic Output of the US Outbreak's Epicenter. Econ Disasters Climate Chang 4(3):561-573 
Gordon S, St-Amour P (2004) Asset returns and state-dependent risk preferences. J Bus Econ Stat 22(3):241-252. https://doi.org/10.1198/073500104000000127

Haigh MS, List JA (2005) Do professional traders exhibit myopic loss aversion? An experimental analysis. J Financ 60(1):523-534. https://doi.org/10.1111/j.1540-6261.2005.00737.x

Halkos G, Zisiadou A (2018a) Examining the natural environmental hazards over the last century. Economics of Disasters and Climate Change 1-32. https://doi.org/10.1007/s41885-018-0037-2

Halkos G, Zisiadou A (2018b) Analysing last century's occurrence and impacts of technological and complex environmental hazards. MPRA No. 90503

Halkos G, Zisiadou A (2018c) Reporting the natural environmental hazards occurrences and fatalities over the last century. MPRA No. 87936

Halkos G, Zisiadou A (2019) An Overview of the Technological Environmental Hazards over the last century. Econ Disasters Climate Chang. https://doi.org/10.1007/s41885-019-00053-Z

Halkos G, Zisiadou A (2020) Is Investors' Psychology Affected Due to a Potential Unexpected Environmental Disaster? J Risk Financial Manag 13(7):151. https://doi.org/10.3390/jrfm13070151

Halkos G, Managi S, Zisiadou A (2017) Analyzing the determinants of terrorist attacks and their market reactions. Econ Anal Policy 54:57-73. https://doi.org/10.1016/j.eap.2017.02.002

Hodgson D (1997) Semiparametric efficient estimation in time series

Jackwerth JC (2000) Recovering risk aversion from option prices and realized returns. Rev Financial Stud 13(2):433-451. https://doi.org/10.1093/rfs/13.2.433

Jennings R, Graham D (1987) Systematic risk, dividend yield and the hedging performance of stock index futures. J Futures Mark 7(1):1-13

Katafuchi Y, Kurita K, Managi S (2020) COVID-19 with stigma: theory and evidence from mobility data. Economics of Disasters and Climate Change 1-25

Kurita K, Managi S (2020) COVID-19 and stigma: Evolution of self-restraint behavior. MPRA No. 103446

Mandel A, Veetil V (2020) The economic cost of COVID lockdowns: An out-of-equilibrium analysis. Econ Disasters Climate Chang 4(3):431-451

Martin A, Markhvida M, Hallegatte S, Walsh B (2020) Socio-economic impacts of COVID-19 on household consumption and poverty. Econ Disasters Climate Chang 4(3):453-479

Mello AS, Parsons JE (2000) Hedging and liquidity. Rev Financ Stud 13(1):127-153

Mello AS, Parsons JE, Triantis AJ (1996) Flexibility or hedging? An error of substitution. Risk 9(10)

Merton RC (1969) Lifetime portfolio selection under uncertainty: the continuous-time case. Rev Econ Stat 247-257. https://doi.org/10.2307/1926560

O’Brien T (1997) Hedging strategies using catastrophe insurance options. Insur Math Econ 21(2):153-162

Pollner JD (2001) Managing catastrophic disaster risks using alternative risk financing and pooled insurance structures. The World Bank

Rosenberg JV, Engle RF (2002) Empirical pricing kernels. J Financ Econ 64(3):341-372. https://doi.org/10. 1016/S0304-405X(02)00128-9

Smith K (1996) Environmental hazards: assessing risk and reducing disaster. University of Cambridge, London and New York, Routledge

Stulz René M (1984) Optimal hedging policies. J Financial Quant Anal 127:140

Viscusi WK (2006) Natural disaster risks: An introduction. J Risk Uncertain 33(1):5-11. https://doi.org/10. 1007/s11166-006-0168-7

Publisher's Note Springer Nature remains neutral with regard to jurisdictional claims in published maps and institutional affiliations. 